\title{
BIOLOGY AND BEHAVIOUR OF THE CERCARIAE OF A SANGUINICOLA SP. IN THE RIVER CILLORUELO (SALAMANCA, SPAIN)
}

\author{
S. MARTIN AND R. VAZQUEZ*
}

\begin{abstract}
SUMMARY. In the light of the hydrodynamic characteristics of the river Cilloruelo (province of Salamanca, Spain) and the results on the shedding of lophocercariae of a Sanguinicola sp. by naturally infected Ancylus fluviatilis, a discussion is made of the influence of different temperatures on shedding and survival of the cercariae. Comments are also made concerning the most likely periods and zones of the river for infection of the definitive host.
\end{abstract}

\section{Biologie et comportement des cercaires d'une espèce de Sanguinicola dans le ruisseau Cilloruelo de la province de Salamanca, Espagne.}

RÉSUMÉ. D'après les caractéristiques hydrodynamiques du ruisseau Cilloruelo (province de Salamance, Espagne) et les résultats de l'émission des lophocercariae d'une Sanguinicola sp. par des Ancylus fluviatilis infectés naturellement, on a fait une discussion sur l'influence de différentes températures dans l'émission et la survie des cercaires.

Aussi on apporte des considérations concernant l'heure la plus probable pour l'infection de l'hôte définitif.

\section{Introduction}

The cercariae is a stage in the life cycle of Digenea whose biological and ecological features, together with the important role it plays in epizootiology has caused it to received a great deal of attention from numerous sources. With respect to the lophocercariae, data have been presented concerning the time of day at which several species are shed (Erickson and Wallace, 1959; Khan, 1961 ; Murty, 1975 and others) and certain evidence has been reported regarding the influence of temperature on shedding and survival. However, up to the present no studies have been carried out which permit the quantitative measurement of the variations of the actual rhythms of these cercariae in conditions of varying abiotic factors such as temperature or the photoperiod, contrary to the case with other Schistosomatidae, namely Schistosoma spp. \footnotetext{
España. Accepté le 5 août 1983 .
}

* Depto. Parasitologia, Facultad de Farmacia (Apartado 449), Universitad de Salamanca, Salamanca 
The present work presents the results obtained from the study of certain aspects of the biology of the cercariae of a Sanguinicola sp. found in Salamanca and describes the possible relationship between their behaviour (observed in experimental conditions) and the hydrodynamic characteristics of the natural environment in which the life cycle of the parasite develops.

\section{Materials and methods}

The speed of the current of the river Cilloruelo was measured following the method described by Schowoerbel (1975) applying a correction factor according to which the average speed of the current is $85 \%$ of the surface value. Temperature was measured fornightly and should therefore only be considered as approximate.

Specimens of Ancylus fluviatilis captured in the river Cilloruelo during the Spring of 1981 and 1982 were kept in a simulated environmental chamber with a photoperiod of $14 \mathrm{~h}$. light and $10 \mathrm{~h}$. darkness at a temperature of $19^{\circ} \pm 1^{\circ} \mathrm{C}$. The water, which was taken from a well, was changed daily.

Once the molluscs shedding the cercariae had been isolated they were placed for periods of 7 days in glass containers with $200 \mathrm{ml}$. of water, which was changed daily. The abovementioned temperature was maintained. Every hour, the cercariae in the containers were counted and this number was subtracted from that of the previous hour, thereby giving the shedding curve of the cercariae. In order to study the influence of temperature on shedding, the infected molluscs were kept in the same conditions as above except that the temperature was altered; values of $15^{\circ}, 20^{\circ}$ and $25^{\circ} \mathrm{C}$ were assayed. Counting was as before and the results correspond to the average shedding by each mollusc. The survival of the free cercariae was studied in numerous populations kept in water at different temperatures. Each hour the number of surviving cercariae was counted until all had died.

\section{Results}

Hydrodynamic characteristics of the aquatic environment. The river Cilloruelo is small and has alternating zones of narrow shallows where the current is strong (facies lotica) and wider depths (facies lentica) where the current is much slower (fig. 1). The current speed is maximum in winter $(40 \mathrm{~cm} / \mathrm{sec})$ in the facies lotica and minimum in summer $(3 \mathrm{~cm} / \mathrm{sec})$ in the facies lentica. Between July and the end of September the current is usually interrupted when the facies lotica dries up.

The seasonal thermal variations undergone by the aquatic medium reflect those taking place in the surrounding environment. Between the months of NovemberMarch, the average temperature of the water does not rise above $8^{\circ} \mathrm{C}$. From March to June a rise in the temperature up to $13^{\circ} \mathrm{C}$ takes place, continuing to rise until a mean of $18^{\circ} \mathrm{C}$ is reached in August, though temperatures of as high as $25^{\circ} \mathrm{C}$ have been recorded in the hottest part of the day. 


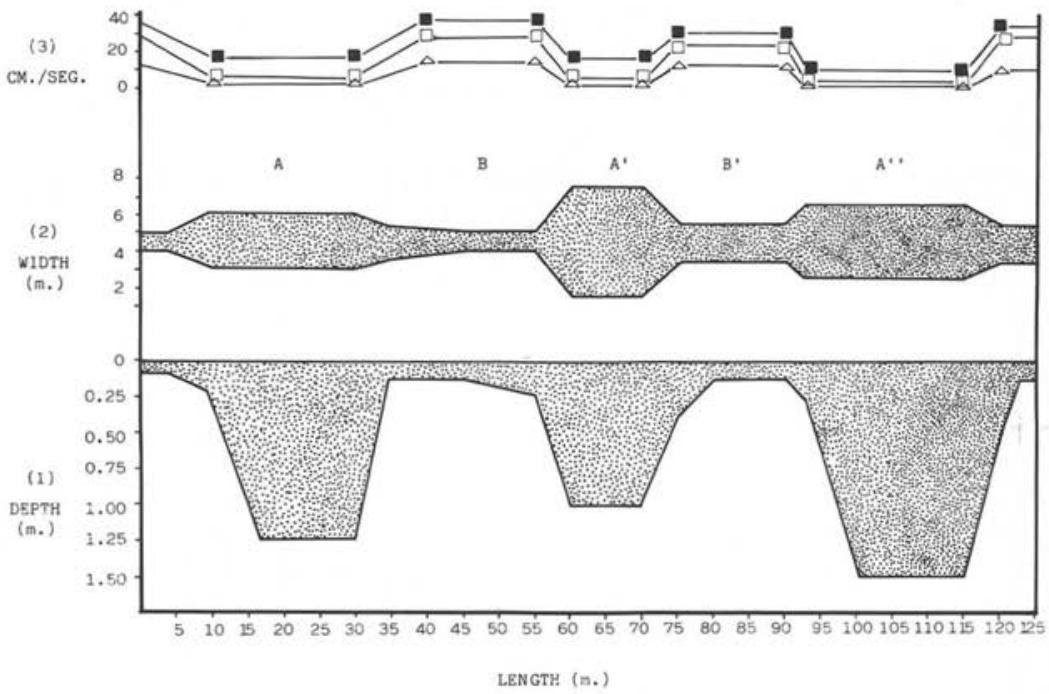

FIG. I. - Profile (I) and overhead view (2) of the stretch of the river Cilloruelo studied.

(3) Seasonal variations of the current speed in the different parts of the stretch studied: - Winter; $\square-\square$ Spring; $\Delta-\Delta$ Summer.

Shedding rhythm of cercariae. Shedding occurs every day (at least in the experimental conditions observed) during a short period of $4-6 \mathrm{~h}$ starting from $15-16.00 \mathrm{~h}$ During the first hour, the shedding is low ; maximum emmision is usually reached between the 2nd and 4th hour, after which it immediately declines and thereafter ceases at $20-21.00 \mathrm{~h}$ ( fig. 2).

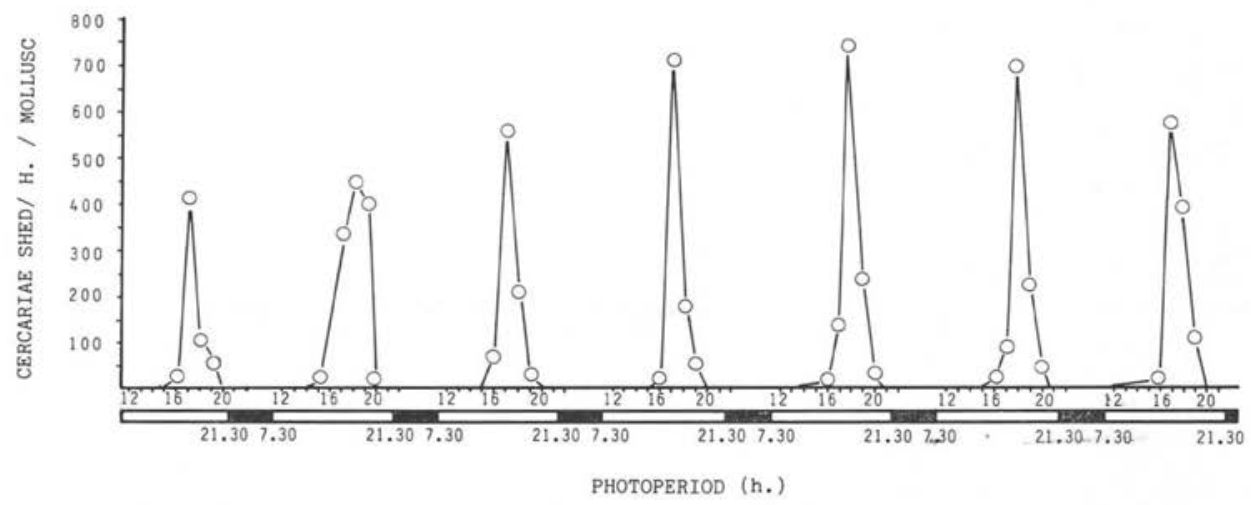

Fig. 2. - Shedding rythm of cercariae of Sanguinicola sp. 
Influence of temperature on shedding. (fig. 3). The molluscs begin to shed cercariae in low numbers $\left(4-8 \mathrm{c} / \mathrm{h}\right.$.) at $10-12^{\circ} \mathrm{C}$. At $15^{\circ} \mathrm{C}$ the numbers of cercariae shed increase, though a maximum is not reached ; rather, a plateau is maintained throughout shedding. At $20^{\circ} \mathrm{C}$ and $25^{\circ} \mathrm{C}$ shedding follows the characteristics pattern and the maximum numbers of cercariae are shed at $20^{\circ} \mathrm{C}$ and almost the double at $25^{\circ} \mathrm{C}$.

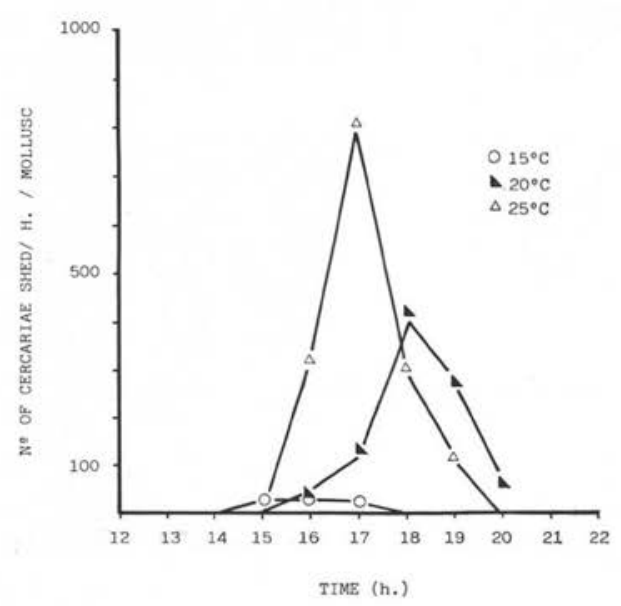

Fig. 3. - Influence of different temperatures on the shedding of cercariae of Sanguinicola sp. by naturally infected A. fluviatilis.

Influence of temperature on longevity of the cercariae. (fig. 4). It is generally known that an increase in temperature causes a decrease in the longevity of the cercariae. Since for the main part of the elimination phase in natural conditions the water temperature ranges between $15^{\circ} \mathrm{C}$ and $25^{\circ} \mathrm{C}$ we have attempted to quantify the survival rate of numerous populations of cercariae at $15^{\circ}, 20^{\circ}$ and $25^{\circ} \mathrm{C}$ under experimental conditions.

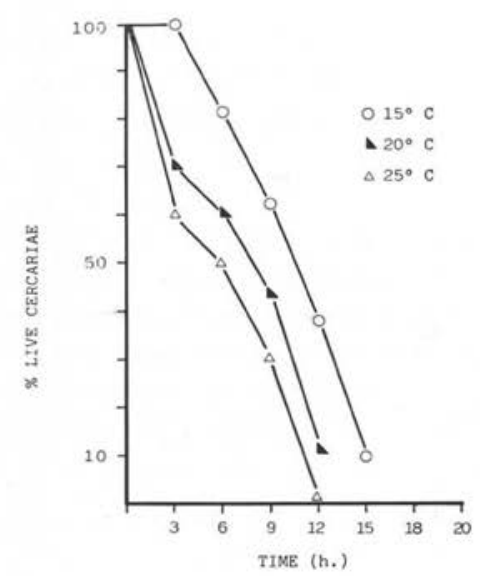

FIG. 4. - Influence of temperature on survival of free cercariae of Sanguinicola sp. 
The difference in survival at $15^{\circ} \mathrm{C}$, on one hand and $20^{\circ}$ and $25^{\circ} \mathrm{C}$, on the other, is reflected in that in the former case the cercariae begin to die at approximately $3 \mathrm{~h}$ after being shed while in the latter they die immediately after being introduced into the aquatic environment.

Behaviour of free cercariae and penetration into the definitive host. These cercariae do not show phototropic behaviour. As long as there are no currents in the containers to drag them along, alternating periods may be observed of upward spiralling and stillness during which they slowly sink to the bottom of the container with the dorsal body fin - acting as a brake, parallel to the surface of the water. No kind of attraction between the experimental definitive host (Rutilus arcasii) and the cercariae could be observed since these latter were seen on numerous occasions to bump into the soft ventral parts of the body and then to drift away. Those observed close to the gills of the definitive host were swept away by the current produced by gill movement. The only way in which the cercariae could come into contact with the fish was when they were dragged along with the water entering the fish's mouth as it aspired water.

Furthermore, experimental infection of the definitive host only occured when the containers were maintained in the dark. In the light, the fish showed excessive activity (possibly due to the experimental conditions and the presence of the observer) which did not allow the cercariae to develop their bathymetric swimming activity since they were continually dragged from one place to another.

\section{Discussion}

It seems that there are numerous patterns of shedding of lophocercariae with reports of nocturnal shedding, shedding in the early morning and also at the end of the afternoon. Our own findings, after repeated studies, show that in the Sanguinicola sp. from Salamanca shedding begins at $15-16.00 \mathrm{~h}$ and finished around 20 $21.00 \mathrm{~h}$.

Theron, Pointier and Combes (1977) and Theron (1982) studied the factors affecting the cercarial density of Schistosoma mansoni. Both works underline the great importance of the hydrodynamic characteristics of the aquatic medium in their dispersion.

In spite of the fact that in our case this kind of study was not carried out in natural conditions, if we take into account the speed of the current of the river between March and July (the months during which the shedding of lophocercariae has been observed) and the experimentally observed data concerning their behaviour it seems highly probable that the lophocercariae are dragged from the facies lotica $\left(\mathrm{B}, \mathrm{B}^{\prime}\right)$ to the pools $\left(\mathrm{A}, \mathrm{A}^{\prime}, \mathrm{A}^{\prime \prime}\right)$ ( fig. 1) where they are able to perform their characteristic swimming. In these latter zones the introduction of cercariae during the hours of shedding is possibly greater than the dispersion caused by the slow current such that maximum concentrations will appear some hours after maximum shedding, perhaps during the early hours of the night. 
In view of our observations that the fish in their natural environment are concentrated almost exclusively in the pools and that experimentally it was only possible to achieve infection in the dark, it is quite feasible that: 1) The probability of infection in the zones of strong current (facies lotica) is practically zero due both to the behaviour of the definitive host and the features of the river Cilloruelo. 2) The majority of infections must take place in the pools where the cercariae are able to develop their bathymetric swimming 3) The risk of infection of the fish is probably highest between the last hours of the afternoon and the first hours of the night.

Most authors seem to be in agreement regarding the behaviour of the cercariae. As far as we know, only Meade (1967) found positive phototropism in the cercariae of Sanguinicola klamathensis. Furthermore, the report by Scheuring (1923) that the cercariae of $S$. inermis attack the gills of carps does not seem to be consistent with the experience of other researchers (Odhner, 1911 and 1923; Schell 1974) nor with our own, according to which penetration seems to take place through the mouth and through the soft parts of the ventral body surfaces (Meade, 1965; Meade and Pratt, 1965 ; Evans and Heckman, 1973 ; Schell, 1974).

\section{REFERENCES}

Erickson D. E., Wallace F. G. : Studies on blood flukes of the genus Sanguinicola. J. Parasitol., I959, 45, 310-322.

Evans W. A., Heckman R. A. : The life history of Sanguinicola klamathensis. Life Sci., 1973, 13, $1285-1291$.

KHAN D. : Studies on larval trematodes infecting-freshwater snails in London (U.K.) and some adjoining areas. Part III " Lophocercous" cercariae. J. Helminthol., I96I, xxxv, 133-I42.

MEAdE T. G. : Description and life-history of Cardicola alseae sp. n. (Trematoda : Sanguinicolidae). Diss. Abstr., 1965, 26, 558 .

MEAdE T. G. : Life history studies on Cardicola klamathensis (Wales, 1958) Meade and Pratt, 1965 (Trematoda : Sanguinicolidae). Proc. Helminth. Soc. Wash., 1967, 34, $210-212$.

Meade T. G., Pratt I. : Description and life history of Cardicola alseae sp. n. (Trematoda : Sanguinicolidae). J. Parasitol., 1965, S1, 575-578.

MurTy A. S. : A new sanguinicolid cercaria from Amnicola travancorica in Andhra Pradesh. Current Sci., 1975, 44, 270-271.

ODHNER T. : Sanguinicola M. Plehn - ein digenetischer Trematode! Mit einem Nachtrag über ältere Beobachtungen von Prof. A. Loos, Kairo. Zool. Anz., I911, 38, 33-45.

ODHNER T. : Remarks on Sanguinicola with a note by W. N. F. Woodland. Qu. J. Micr. Sc. N. S., I924, 68, 403-4II.

Schell S. C. : The life history of Sanguinicola idahoensis sp. n. Trematoda: Sanguinicolidae) a blood parasite of steelhead trout, Salmo gairdneri Richardson. J. Parasitol., 1974, 60, 56I-566.

ScheUring L. : Der Lebenscyklus von Sanguinicola inermis Plehn. Zool. Jd. Abt. Anat., 1922, 44, 265-310.

Schowoerbel J. : Métodos de hidrobiología. Ediciones Hermann Blume, Madrid, 1975, 262.

THERON A. : Ecology of schistosome cercarian transmission : production, emergence, dispersion and infectivity of Schistosoma mansoni cercariae. Parasites-Their world and ours. Edit. Proc. Fifth Intern. Cong. of Parasitol. Toronto, Canada, D. F. Mettrick and S. S. Desser, rooo AE Amsterdam, 1982, 465 .

Theron A., Pointier J.-P., Combes C. : Recherches sur les facteurs responsables des densités de cercaires de Sohistosma mansoni en Guadalupe. Ann. Parasitol. Hum. Comp., 1977, s2, 421-433. 